\title{
Numerical analysis of the tool wear effect in the machining induced residual stresses
}

\author{
A. Muñoz-Sánchez, J.A. Canteli, J.L. Cantero, M.H. Miguélez* \\ Department of Mechanical Engineering, Universidad Carlos III de Madrid Avda. Universidad 30, Leganés 28911, Madrid, Spain
}

Keywords:

Numerical modelling

Finite element

Residual stresses

Tool wear

Orthogonal cutting

\begin{abstract}
Machining is a dynamic process involving coupled phenomena: high strain and strain rate and high temperature. Prediction of machining induced residual stresses is an interesting objective at the manufacturing processes modelling field. Tool wear results in a change of tool geometry affecting thermo-mechanical phenomena and thus has a significant effect on residual stresses. The experimental study of the tool wear influence in residual stresses is difficult due to the need of controlling wear evolution during cutting. Also the involved phenomena make the analysis extremely difficult. On the other hand, Finite Element Analysis (FEA) is a powerful tool used to simulate cutting processes, allowing the analysis of different parameters influent on machining induced residual stresses.

The aim of this work is to develop and to validate a numerical model to analyse the tool wear effect in machining induced residual stresses. Main advantages of the model presented in this work are, reduced mesh distortion, the possibility to simulate long length machined surface and time-efficiency. The model was validated with experimental tests carried out with controlled worn geometry generated by electro-discharge machining (EDM). The model was applied to predict machining induced residual stresses in AISI $316 \mathrm{~L}$ and reasonable agreement with experimental results were found.
\end{abstract}

\section{Introduction}

Machining is a dynamic process involving high strain rate, elevated strain and high temperature in the workpiece. One of the most important characteristics of the machined surface integrity is the level of tensile residual stress induced during machining. The analysis of residual stresses due to machining operations has been an active subject of research. The reliability of structural components obtained by machining operations is influenced by the state of residual stresses resulting from processing. Tensile residual stresses in the vicinity of the machined surface, has negative effects on fatigue, fracture resistance and on stress corrosion and therefore can substantially reduce the component life [1]. The residual stress level is strongly related to both mechanical and thermal phenomena induced during chip removal [2]. As is well known these phenomena depend on the tool geometry.

During cutting, tool geometry is changed due to the tool wear effect. Depending on the type of tool wear, the change of the contact surface in the interface chip/tool is produced together with a variation of the effective tool rake angle. Moreover an increase of the contact area between clearance surface and machined surface is observed. In general, different wear mechanisms occur simultaneously during cutting operation, thus it is not easy to carry out experimental analysis due to the impossibility to control both, type and level, of tool wear during machining tests. Depending on cutting conditions, tool

\footnotetext{
* Corresponding author. Tel.: +34 9162494 02; fax: +34 916249430.

E-mail address: mhmiguel@ing.uc3m.es (M.H. Miguélez).
} 
material and workpiece material, one type of wear is prevalent over the rest. Main progressive wear types observed in cutting tools are flank wear, usually observed at intermediate cutting speed; and crater wear, commonly related to high-speed machining [3]. In this work it is also considered the influence in residual stresses of rounded cutting edge. The cutting edge radius is always larger than zero and it is influenced by several factors, not only by cutting evolution, but also by coating layers or the initial definition of cutting edge [4].

The effect of tool wear in the component surface integrity has been received considerable attention in scientific literature. Liu and Barash [5] observed significant influence of tool geometry in residual stresses induced by orthogonal cutting of low carbon steel. Similar trend was observed by Liu et al. [6] in the case of hard turning of bearing steel. Enhanced level of tensile residual stress at the machined surface due to the rounded cutting edge was observed by Thiele et al. [7] when machining AISI 52100 and Arunachalam et al. [8] in the case of Ni alloy Inconel 718. Changes in the clearance angle and flank wear also influence tensile level of residual stresses due to the increased amount of friction heat generated in this zone, as was shown by Chen et al. [9]. On the other hand the influence of chamfer tool geometry, directly related with effective rake angle, was studied by Hua et al. [10].

Most works referred in literature, develop experimental approaches to study the influence of tool wear in residual stresses; however, numerical approaches have also been used to predict the influence of tool wear and geometry in surface integrity [1,11-13]. Finite element is a powerful tool to analyse the effect of different factors involved in generation of residual stresses because it is possible to uncouple different contributions [2] and has been extensively used for decades to simulate cutting.

Commercial FE codes, mainly DEFORM and ABAQUS, have been used to predict residual stresses in orthogonal cutting. The commercial FE software DEFORM-2D is a Lagrangian implicit code with adaptive remeshing [10,11], meanwhile ABAQUS is one of the most versatile general-purpose code allowing both ALE and Lagrangian analysis, as well as implicit and explicit integration schemes $[12,13]$. ALE formulation presents advantages when compared with the Lagrangian approach and has been widely used to simulate residual stresses using ABAQUS code. The model commonly used to predict residual stresses in literature is described in detail in $[2,12]$ and it is schematically shown in Fig. 1.

Main drawback of this model is the necessity to define the chip geometry and its mesh in order to deal with the high level of distortion that appears in this zone. An iterative work is needed to obtain the precise geometry and appropriate mesh that are able to deform without stopping the calculation due to distortion. Another problem is workpiece elements enlargement, especially those located at the interface chip-tool, due to the use of Lagrangian boundary in the upper contour of the chip.

One of the main machining simulation drawback, especially in case of residual stresses simulation, is the extremely high computational cost of simulations. A computational time of days or even weeks may be needed even to simulate few milliseconds of orthogonal cutting using 2D models. This very low time introduces several problems if the focus of the analysis involves thermal issues, related to heat generation and diffusion into the tool [14,15]. In fact, no steady-state conditions are reached during the numerical simulation. Technical literature shows that it is relatively easy to predict some process variables such as cutting and thrust force, the chip geometry, shear angle and the contact length [16] however, numerical prediction becomes poor when temperatures on the rake face and inside the tool are investigated [17]. In case of residual stresses simulation strongly dependent on thermal phenomena, it is necessary to simulate a long length machined surface to ensure steady state conditions and stabilized level of residual stresses at the machined surface.

It is commonly admitted that tensile residual stresses in machining result from heating the machined surface during the cutting operation. The high temperature level reached in a thin thermally affected layer near the workpiece surface produces thermal expansion and plastic flow. During the subsequent cooling, the thermal contraction of this layer is higher than the one reached in-depth in the workpiece, and this phenomenon is believed to be at the origin of tensile residual stresses observed in machining. Although common understanding is that, in absence of thermal effects the mechanical loading exerted onto the workpiece leads to compressive residual stresses; it is shown in $[2,18]$ that even in absence of thermal effects, a substantial level of tensile residual stresses can be obtained by solely pure mechanical effects. However the level of tensile residual stress is also strongly influenced by thermal effects, thus the prediction of temperature should be as

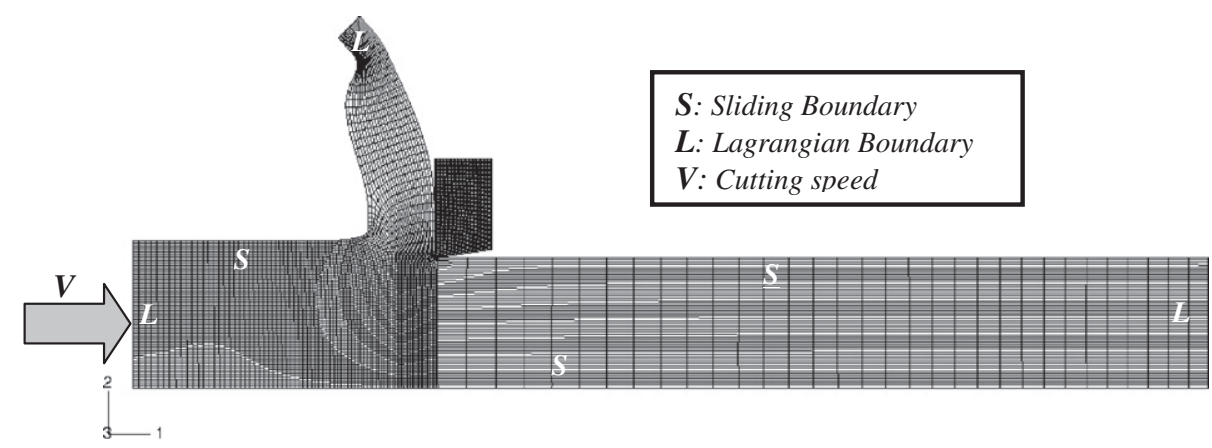

Fig. 1. Type of contour used in model commonly used in ALE formulation with ABAQUS to predict residual stresses. See details in [2,19]. 
accurate as possible when the prediction of residual stresses is the objective. In consequence it is critical to achieve steadystate conditions during calculation, being necessary to simulate large cutting time.

On the other hand, the analysis should be performed in two phases, first the cutting process is simulated and second the workpiece is cooled down and unloaded. Most works based in ABAQUS used explicit integration scheme in both phases, being the second phase extremely time consuming. In a recent work, Nasr et al. [19] developed an efficient model with an integration explicit scheme for the cutting phase and an implicit scheme for the unloading and cooling phase. Conditional stability is the only concern about explicit integration, requiring a very small time step. This time is in the order of the time required by a dilatational wave to cross the smallest element in the mode, typically around $10^{-9}-10^{-10} \mathrm{~s}$, leading to large calculation time. This phase time-efficiency can be improved with the use of mass scaling as has been reported in literature [20]. Implicit integration is unconditionally stable and the only limitation on time step is the solution convergence, which is based on a pre-defined criterion. The use of implicit integration in the second phase of the analysis diminishes significantly the calculation time from several days (obtained with explicit integration) to several minutes.

The main objective of this work is to analyse the influence of tool wear on residual stresses in metal cutting developing a numerical model based on the finite element technique. The model presented in this work is a modification of the model commonly used in literature when predicting residual stresses with ALE formulation in ABAQUS, described in [12,20], that has proved its accuracy for prediction of machining induced residual stresses [2]. Although the results obtained with this previous model have been satisfactory, the preparation process of the model (initial geometry of the chip and meshing) has been a time consuming step of the work, due to the need of several iterations before obtaining a mesh able to complete the desired cutting time. The new model was developed in order to improve main drawbacks of the early approach [21]. The use of Eulerian boundaries at the workpiece entrance and at the chip, diminished significantly the number of iterations needed to generate a previous geometry and its associated mesh, due to the low level of distortion in the zone around the tool tip obtained with the Eulerian boundary at the chip. The boundaries also allow the model to maintain a constant size in the element at the interface improving the precision of the calculation of different magnitudes in this zone. It was also possible to simulate a long length cut, reaching steady-state conditions. In order to obtain a time efficient method, analysis was carried out in two phases. First, using an explicit integration scheme, cutting was modelled and steady-state conditions were reached. Second, the workpiece was unloaded and cooled by an implicit integration scheme recently proposed in [19].

Main contribution of the present work can be summarized as follows. The geometry of the basic model (corresponding to new tool) was modified to reproduce geometrical changes related with tool wear, and was used to analyse the effect of tool wear evolution in orthogonal cutting of AISI $316 \mathrm{~L}$. Most common types of wear related with loss of tool material and consequently with changes in tool geometry; flank wear, rounded cutting edge and crater wear; were studied. Orthogonal cutting tests were carried out in order to validate the numerical model. It was necessary to generate artificially worn geometry using EDM to machine carbide tool. Numerical results were compared with experimental results showing good agreement and thus the ability of the model to predict residual stresses when machining with both new and worn tool, as is shown in the following sections.

\section{Numerical model}

\subsection{Model description}

A plane strain ALE model was developed using the commercial Finite Element code ABAQUS/Explicit. Eulerian, Lagrangian and Arbitrary Lagrangian-Eulerian (ALE) techniques have been used to simulate orthogonal cutting. In Lagrangian analysis, the computational grid deforms with the material whereas in Eulerian analysis it is fixed in space. The Lagrangian calculation embeds a computational mesh in the material domain and solves for the position of the mesh at discrete points in time [22]. The Eulerian formulation has been used to model orthogonal metal cutting as a steady process of chip formation [23]. ALE is a relatively new modelling technique in machining, including a combination of the Lagrangian and Eulerian approaches without having their drawbacks. It was firstly introduced to model the cutting process by the end of the last decade. Some of recent ALE cutting models were presented in [24-26]. This approach became popular due to its implementation in commercial finite element codes. Explicit dynamic ALE formulation is very efficient for simulating highly non-linear problems involving large localized strains. Detailed formulation for an ALE approach can be found in different papers, see for instance [26].

One of the model objectives is to avoid mesh distortion for the tool initial geometry and also when the tool worn geometries are considered. The residual stress distribution at the machined surface should be stabilized and steady-state conditions should be reached. A thermo-mechanical coupled analysis was developed using CPE4RT element type, see ABAQUS manual [27], that are plane strain, quadrilateral, linearly interpolated, and thermally coupled elements with reduced integration and automatic hourglass control, for ALE formulation.

Analysis was carried out in two steps: first cutting, using an explicit integration scheme; and second, cooling and unloading, using an implicit integration scheme proposed in [19]. The residual stress distribution was averaged from a small zone of the workpiece corresponding to stationary conditions during cutting and stabilized level of residual stress.

The basic geometry and dimensions of the numerical model are shown in Fig. 2, corresponding to a new tool. This reference geometry of the model was modified in order to simulate the geometrical effect on different type and stages of tool 


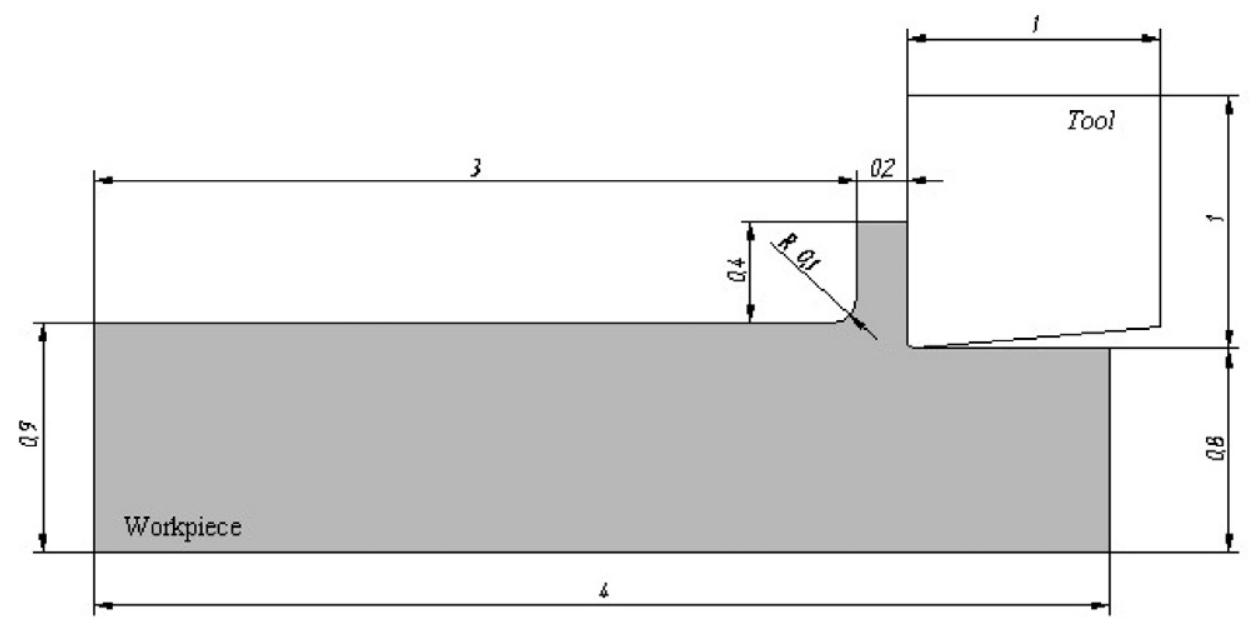

Fig. 2. Basic undeformed geometry of the numerical model (dimensions in $\mathrm{mm}$ ).

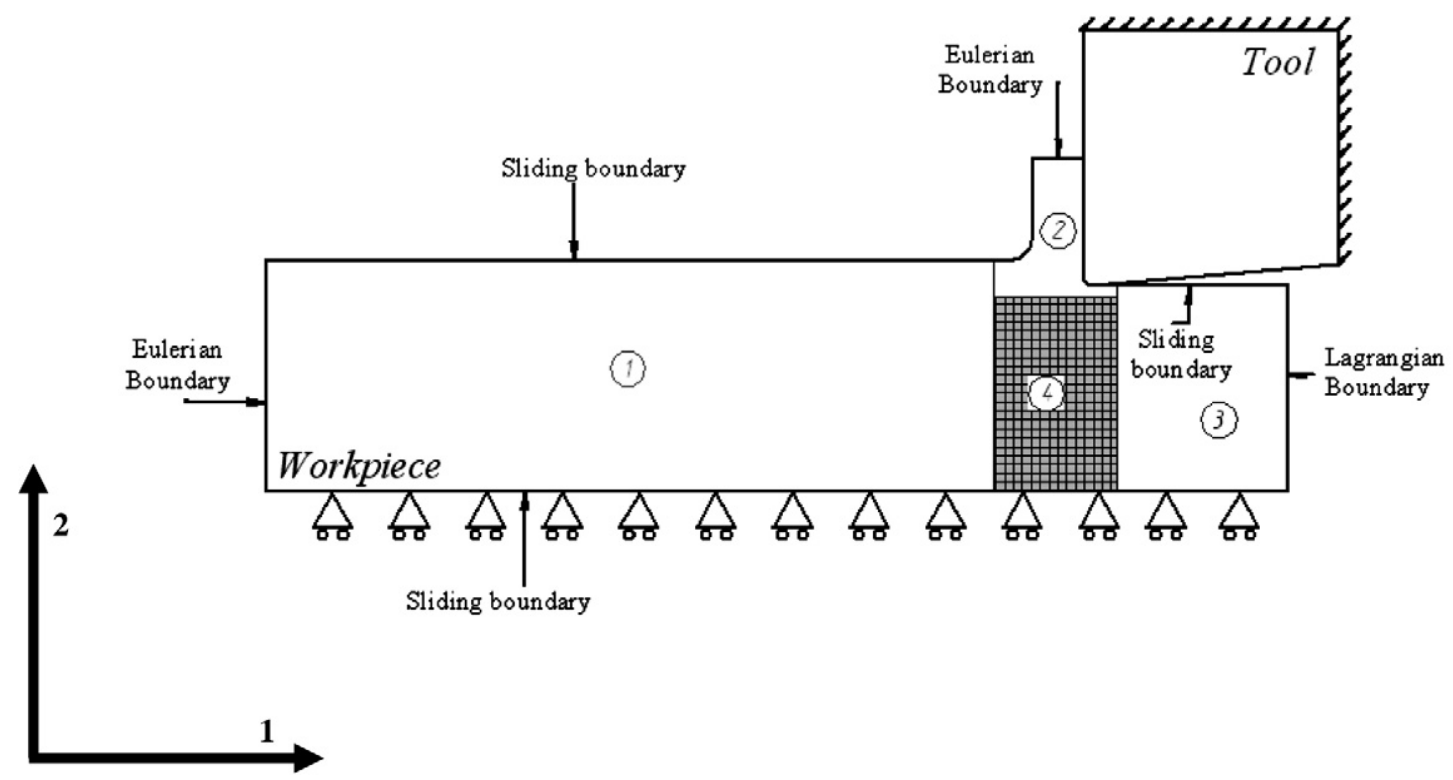

Fig. 3. Implementation of boundary condition and type of contour in the model. Regions 1-3 combine sliding and Lagrangian/Eulerian boundaries. Region 4 Eulerian.

wear. The undeformed mesh geometry in the case of new tool, presenting the main characteristics of the model is shown in Fig. 3.

The tool was fixed and the cutting speed was applied to the workpiece. Cutting took place in the plane 1-2 under plane strain conditions. Continuous chip formation was assumed. The depth of the workpiece was selected taking into account the typical profile of machined induced residual stresses. On the other hand, it is important to note that the dimensions of the undeformed chip (curvature radius and width) are not critical, and thus, changes in these magnitudes lead to successful calculations with the model. The sensibility of the model when these variables vary is not so accused as in the case of the previous model, in which several iterations were needed before obtaining a geometry able to perform the calculation during the desired cutting time.

The ALE model uses sliding, Lagrangian and Eulerian contours (see ABAQUS user manual [27]) allowing the material to flow across an internal Eulerian zone surrounding the tool tip. This approach avoids extreme mesh distortion, allowing the simulation of a long machined surface (larger than $15 \mathrm{~mm}, 150$ times the value of the uncut thickness of the chip equal to $0.1 \mathrm{~mm}$ ).

The model was divided in several zones allowing mesh motion or material flow across the fixed mesh, depending on the zone considered in the model (see Fig. 3). Zones 1-3 combine Lagrangian/Eulerian boundaries with sliding boundaries (where the material is allowed to flow tangential to the contour and not allowed to go across this boundary). Eulerian 
boundaries at the entrance of the zone 1 and in the zone 2 (chip) avoid the distortion that usually appears as the calculation advance. Zone 4 is an Eulerian region, with the mesh fixed, allowing the material to flow across this region.

The main advantage of this technique was the low level of distortion in the region surrounding the tool tip. Thus it was possible to simulate both large machined surface (that is necessary to obtain stabilized residual stresses) and tool wear geometries related with highly negative local rake angle (for instance the case of rounded cutting edge).

Deformed mesh during cutting simulation is shown in Fig. 4. Low mesh distortion is achieved in the zone surrounding the tool tip, the chip curvature and the tool-chip interface. The statement of Lagrangian contour at the upper border of the chip usually leads to element distortion in these areas causing termination of the simulation, especially when highly negative rake angle is simulated or when the initial geometry of the chip has not been properly defined $[2,12]$.

As is widely accepted in literature [28], a value of the Quinney-Taylor coefficient equal to 0.9 was assumed. An initial temperature of $293 \mathrm{~K}$ was imposed. Conduction and convection to air (only in freshly machined surface) were taken into account, radiation was neglected. The heat convection coefficient was $20 \mathrm{~W} / \mathrm{m}^{2} \mathrm{~K}$ and sink temperature was $293 \mathrm{~K}$. Thermal flux was allowed in the attached contour of the tool.

Friction is one of the hardest phenomena to simulate in machining. In the present work, a constant coefficient of friction along the tool/workpiece contact length was assumed. Although it is the simplest formulation, it has been widely used in numerical simulation of machining [29]. The value of the friction coefficient equal to 0.4 reproduces accurately the resultant residual stress observed in experimental tests, as will be shown later. The heat partition between tool and workpiece was assumed to be $50-50 \%[30]$.

The workpiece material was modelled using the Johnson-Cook constitutive model [31]:

$$
\sigma_{Y}=\left(A+B\left(\varepsilon^{p l}\right)^{n}\right) \cdot\left(1+C \ln \left(\frac{\dot{\varepsilon}^{p l}}{\dot{\varepsilon}_{0}}\right)\right) \cdot\left(1-\left(\frac{\theta-\theta_{\text {ref }}}{\theta_{\text {melt }}-\theta_{\text {ref }}}\right)^{m}\right)
$$

Being, $\sigma_{Y}$ the flow stress, $\varepsilon^{p l}$ the equivalent plastic strain, $\theta$ the temperature, and all remaining parameters, material constants. This constitutive equation, available in ABAQUS/Explicit, is useful to simulate mechanical processes involving high strain and strain rates, and thermal softening, and it has been widely used to model cutting processes [32].

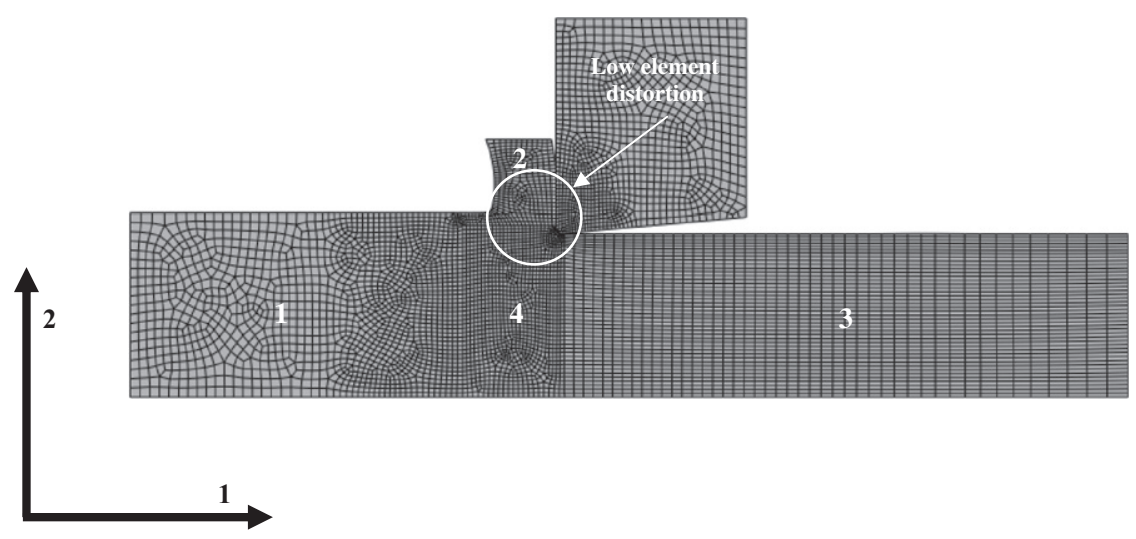

Fig. 4. Deformed mesh during cutting simulation. Regions 1-3 combine sliding and Lagrangian/Eulerian boundaries. Region 4 is Eulerian.

Table 1

Constitutive equation parameters [33].

\begin{tabular}{llllll}
\hline$A(\mathrm{MPa})$ & $B(\mathrm{MPa})$ & $n$ & $C$ & $m$ & $\dot{\varepsilon}_{0}\left(\mathrm{~s}^{-1}\right)$ \\
\hline 514 & 514 & 0.508 & 0.042 & 0.533 & $10^{-3}$ \\
\hline
\end{tabular}

Table 2

Tool material properties [34].

\begin{tabular}{lc}
\hline Properties & Carbide tool \\
\hline Density $\left(\mathrm{kg} / \mathrm{m}^{3}\right)$ & 14,900 \\
Specific heat $\left(\mathrm{J} / \mathrm{kg}^{\circ} \mathrm{C}\right)$ & 138 \\
Thermal conductivity $\left(\mathrm{W} / \mathrm{m}^{\circ} \mathrm{C}\right)$ & 79 \\
\hline
\end{tabular}


Characterization of workpiece material AISI $316 \mathrm{~L}$ has received considerable attention in the literature. It is possible to find Johnson-Cook parameters in a wide range of values, associated to the thermo-mechanical behaviour of this alloy. In this work parameters presented in Table 1, proposed in [33] have been used. Physical properties of cutting material (cemented carbide) and workpiece material were obtained from scientific literature [32,34] and are presented in Tables 2 and 3.

Table 3

Workpiece material properties [32].

\begin{tabular}{ll}
\hline Properties & AISI $316 \mathrm{~L}$ \\
\hline Young modulus $(\mathrm{GPa})$ & 202 \\
Poisson coefficient & 0.3 \\
Density $\left(\mathrm{kg} / \mathrm{m}^{3}\right)$ & 7800 \\
Specific heat $\left(\mathrm{J} / \mathrm{kg}^{\circ} \mathrm{C}\right)$ & 542 \\
Thermal expansion coefficient & $1.99 \mathrm{E}-5$ \\
Thermal conductivity $\left(\mathrm{W} / \mathrm{m}^{\circ} \mathrm{C}\right)$ & 20 \\
\hline
\end{tabular}

$\mathbf{a}$

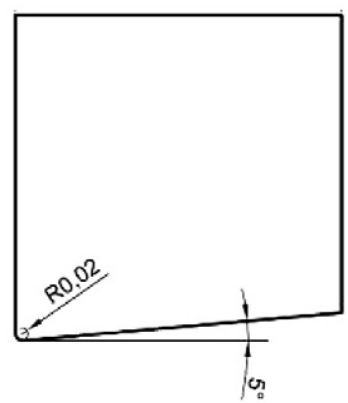

b
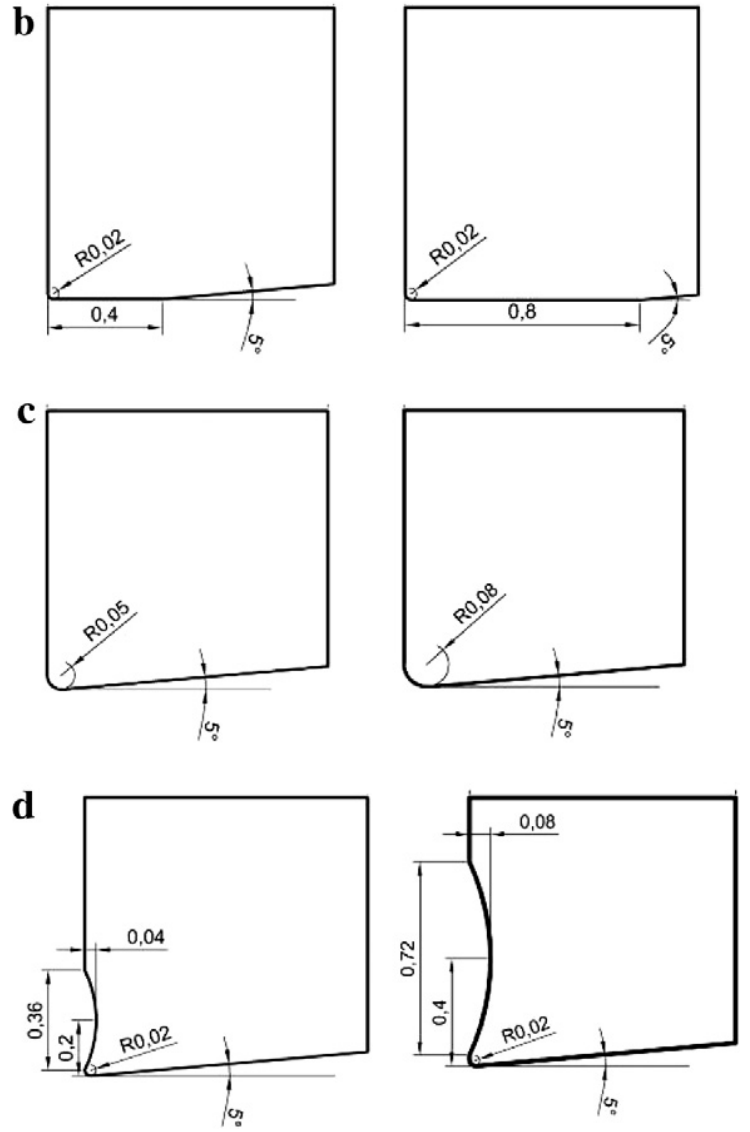

Fig. 5. Tool geometry to simulate wear: (a) Reference (new tool). (b) Flank wear. (c) Rounded cutting edge. (d) Crater. 


\subsection{Modelling worn geometry}

As was explained before main types of tool wear were analysed. The study was focused in the geometrical aspects of tool wear, i.e. other aspects like changes in contact properties are not taken into consideration. Basic geometry of the reference new tool is shown in Fig. 5a.

This basic geometry of the model was modified in order to simulate two levels of each type of wear: flank wear, rounded cutting edge and crater wear. Fig. 5b-e shows the tool geometry corresponding with each type and level of tool wear. Geometrical characteristics of the worn tool have been stated from common values referred in literature for different machining operations.

\section{Experimental work and model validation}

\subsection{Cutting tests}

Orthogonal dry cutting tests were carried out in a lathe (PINACHO model Smart-Turn 6/165) with the following parameters: cutting speed $120 \mathrm{~m} / \mathrm{min}$, feed rate $0.1 \mathrm{~mm} / \mathrm{rev}$, cutting width $2 \mathrm{~mm}$. The workpiece material was AISI $316 \mathrm{~L}$ steel tube, wall $2 \mathrm{~mm}$ thick.

Tool wear evolution is a complex process depending not only on workpiece and tool characteristics, but also on cutting and operation parameters such as the use of lubricant. It was decided to generate artificially the final geometry of the tool instead of using worn tools after a certain cutting time because it is not possible to control wear evolution during current machining processes. This decision allowed checking different typical worn geometries with a controlled level of wear using the same workpiece material and cutting parameters.

The worn geometries of the tools presented in Fig. 5 were generated by electro-discharge machining (EDM) on cemented carbide tool material. The rake angle and the clearance angle were $0^{\circ}$ and $5^{\circ}$ respectively. The main objective of the experimental work was to perform tests with a known worn geometry in order to validate the model by comparing numerical and experimental results.

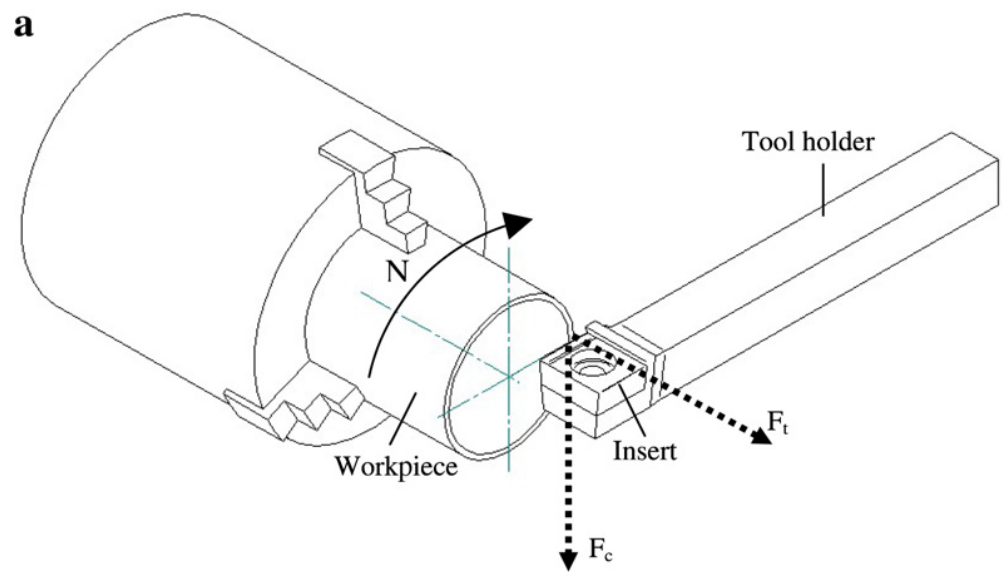

b

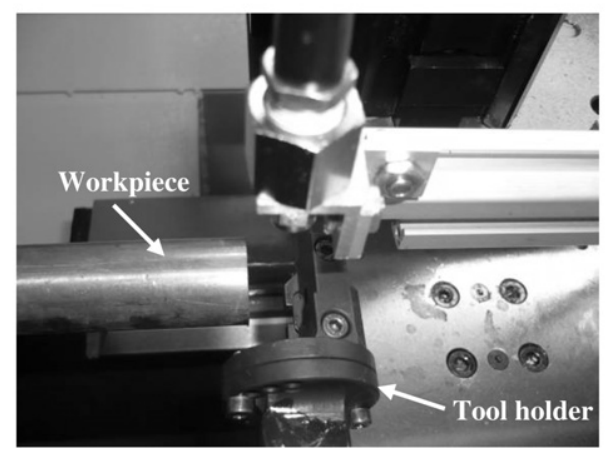

Fig. 6. (a) Scheme of orthogonal cutting tests. (b) Detail of the tool holder instrumented to measure cutting forces in the lathe. Circumferential direction corresponds with direction 1 in the model. 
The support of the tool was instrumented with strain gages with the aim of measure the cutting forces during the orthogonal cutting of the tube. The cutting edge of the insert was located coaxial to the axis of the support, avoiding the effect of torque during cutting (Fig. 6a and b). Cutting and trust forces predicted with numerical model matched reasonably the values measured in the cutting tests in the lathe. Differences below $15 \%$ were obtained.

More details of the experimental work can be found in [35].

Table 4

Parameters involved in the X-ray analysis.

\begin{tabular}{ll}
\hline Parameter & Condition \\
\hline Equipment & StressTech/Xstress 3000 \\
Power & $30 \mathrm{kV}, 6,7 \mathrm{~mA}$ \\
Material phase & $\mathrm{Fe} \gamma($ ferrite $)$ \\
Spot diameter $(\mathrm{mm})$ & 2 \\
$\frac{1}{2} S_{2\{h k l\}}\left(\mathrm{MPa}^{-1}\right)$ & $7.036 \mathrm{E}-6$ \\
$S_{1\{h k l\}}\left(\mathrm{MPa}^{-1}\right)$ & $-1.597 \mathrm{E}-6$ \\
Wavelength-radiation & $\mathrm{Mn} \mathrm{K} \alpha$ \\
Filter & $\mathrm{Cr}$ \\
Bragg angle $\left(^{\circ}\right)$ & 152.26 \\
\hline
\end{tabular}
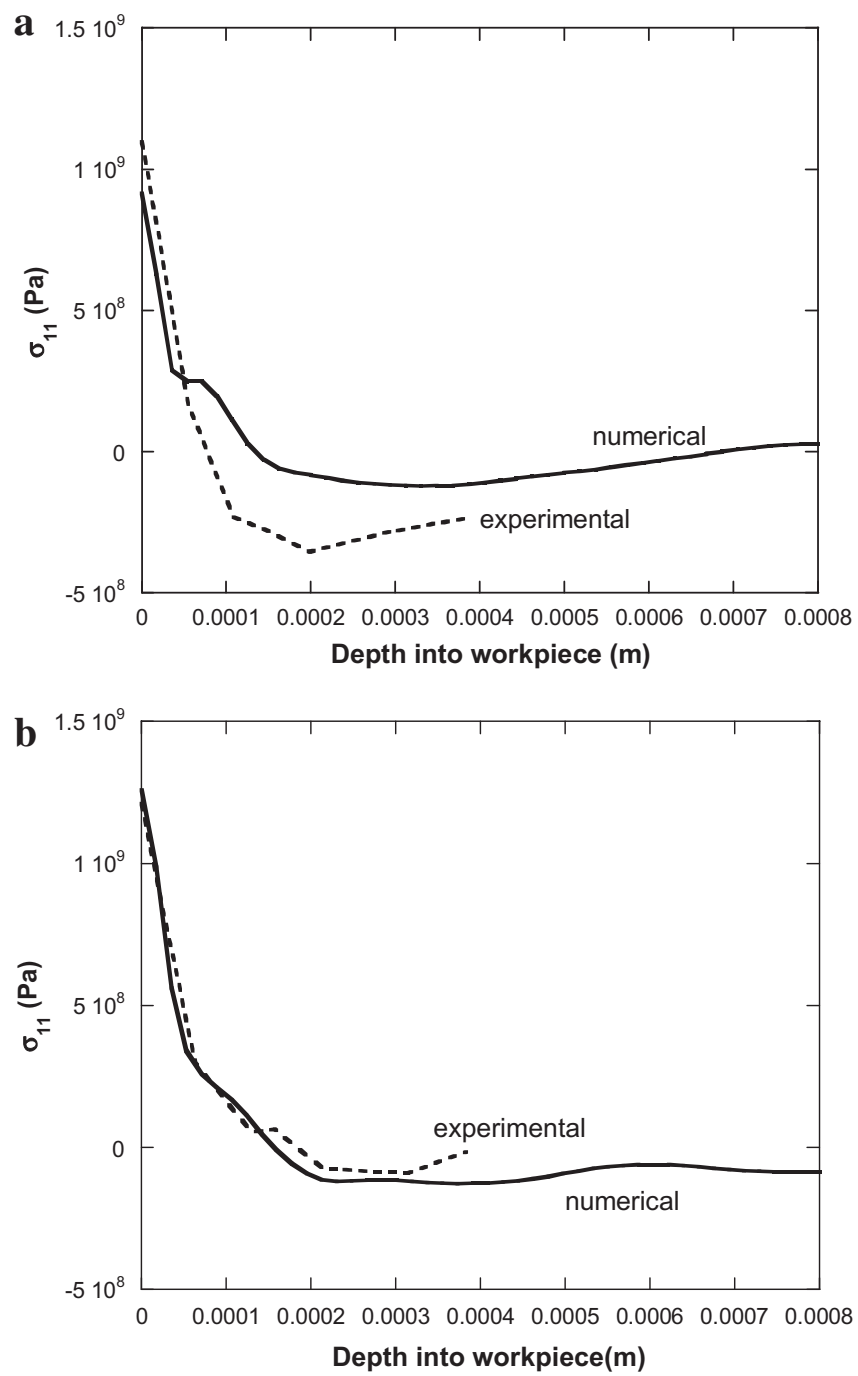

Fig. 7. Experimental and numerical residual stress in circumferential direction (1) obtained after machining with new tool (a) and worn tool (b, cutting edge radius $0.05 \mathrm{~mm}$ ). 


\subsection{Measurement of residual stresses}

Residual stresses at the machined surface were obtained in the circumferential direction (corresponding to direction 1 in Fig. 3) after turning tests. In the case of reference geometry and rounded cutting edge (radius $20 \mu \mathrm{m}$ and $50 \mu \mathrm{m}$ ) the in-depth distribution of residual stress was also obtained.

The residual stress state in the machined surface and subsurface layers of the workpiece was analysed at the technological centre IDEKO [36] using the X-ray diffraction technique. To determine the in-depth residual stress profiles, successive layers of the material were removed by electropolishing, to avoid the reintroduction of residual stress. The residual stresses were evaluated by the $\sin ^{2} \psi$ method from the elastic strain distribution obtained from the interreticular plane spacing. The elastic radio-crystallographic constants, $\frac{1}{2} S_{2\{h k\}}$ and $S_{1\{h k l\}}$, [37] are given in Table 4 with other parameters involved in the X-ray study.

Fig. 7 shows the comparison between predicted residual stresses and in-depth distribution measured. From Fig. 7, it is possible to deduce that the model was able to predict distribution of residual stresses with reasonably accuracy (maximum difference between predicted and measured stresses at machined surface around 15\%).

\section{Numerical results and discussion}

In this section, numerical results obtained in simulations with new and worn geometry are presented and compared with those values of residual stresses measured at machined surface after orthogonal turning tests. It is worth to note that predicted residual stresses should be simulated and extracted from the FE model under the same conditions as those applied experimentally. Several useful recommendations concerning the validity of this procedure can be found in a recent work in the literature [38]. Concerning the extraction of residual stresses from the FE model, it was highlighted the importance to obtain stress profiles far away from the chip formation zone in order to ensure the stabilization of the stress level. It was also stated the interest to simulate several cutting passes to account for the previous state of the machined surface. On the other hand, predicted residual stress should be averaged over a finite volume of the work material. Some precautions should also be adopted during the experimental procedure. It is important to control tool wear during the machining tests and wear must be taken into account when modelling the residual stresses.

Most recommendations have been followed in this work, except for simulating several passes, because of the complexity of modelling previous cut with ALE approach. This effect could cause obtaining lower levels of stress from FE model than those measured, as is explained later in this section.

Residual stresses result from a complex interplay between thermal and mechanical effects. It is widely accepted that tensile stresses are related to thermal expansion effects. It has been shown that in cutting operations, pure mechanical effects can also contribute to develop tensile residual stresses. Indeed, it was demonstrated that tensile residual stresses could be generated near the machined surface even in the absence of thermal expansion. A parametric analysis developed in [2] showed that the level of tensile stresses is higher when thermal expansion is increased and thermal softening is decreased. Note that the increase of tool wear is usually related with higher level of temperature having both opposite effects.

On the other hand it was demonstrated that the decrease of effective rake angle results in a decreased tensile level of residual stress due to the position of stagnation point during cutting [2]. It is possible to deduce by observing the velocity

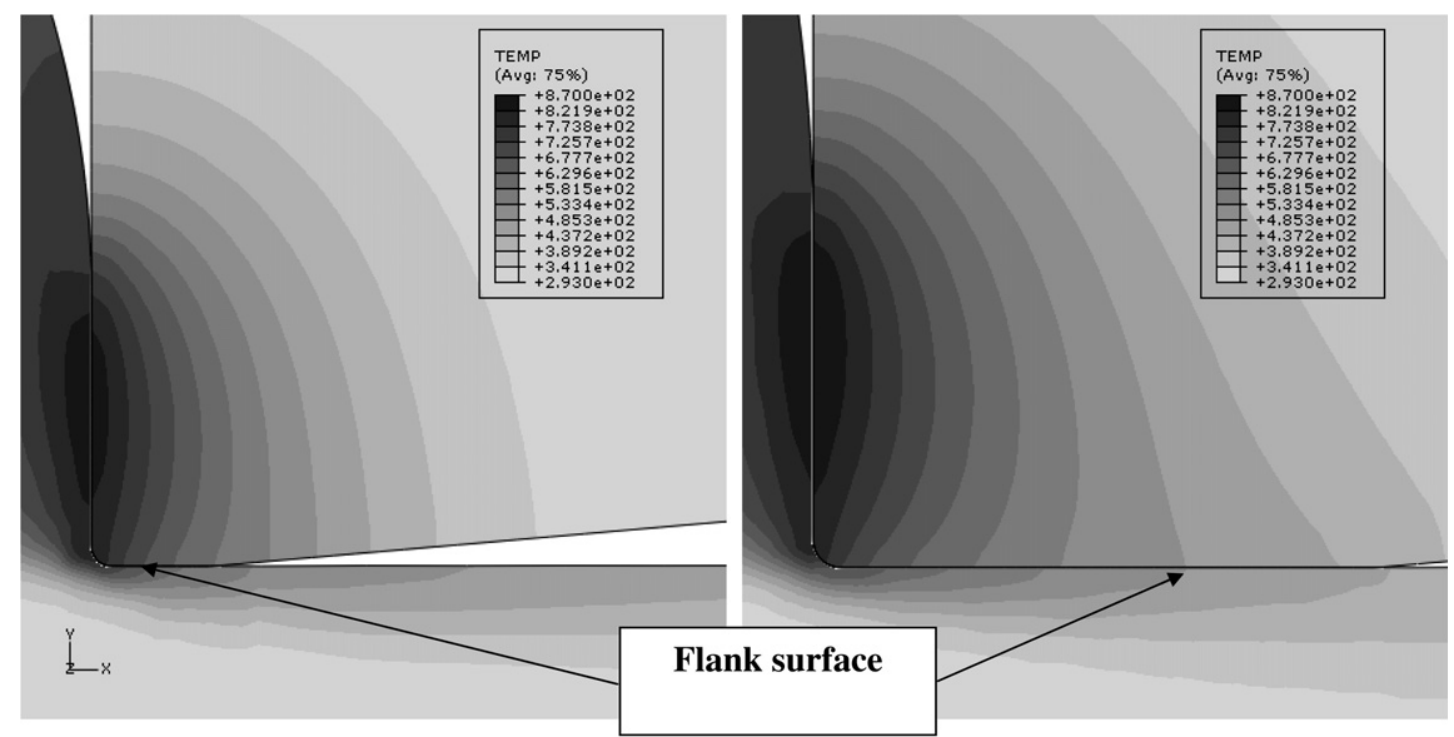

Fig. 8. Temperature field obtained during cutting with flank wear equal to $0.1 \mathrm{~mm}$ (left) and $0.4 \mathrm{~mm}$ (right). 
field, that increasing the zone where the velocity magnitude is very small, the sticking of the chip with the tool rake face is enhanced. This phenomenon provides an effective value of the rake angle which is smaller than the real value, diminishing the level of the residual stresses.

Both effects, increased temperature and changes in the stagnation zone, can be observed when machining with worn tools. In the following sections each type of wear is analysed. The temperature and velocity fields are studied in order to evaluate both opposite contributions to residual stresses. The level of tensile residual stress predicted at the machined surface is presented together with the values measured after machining tests. As can be appreciated in the following sections, in most cases, experimental tensile values at the machined surface are larger than predicted values. This behaviour could be related with the effect of the previous cut that appears in the turning tests. In the experimental tests used to validate simulations, the main cutting edge cuts the machined surface generated in the previous lathe revolution. In the case of difficult to cut materials, like AISI $316 \mathrm{~L}$, this zone is strongly affected by the previous cut [39] increasing the induced residual stresses in the workpiece. This increment could explain the differences observed between predicted and measured residual stresses.

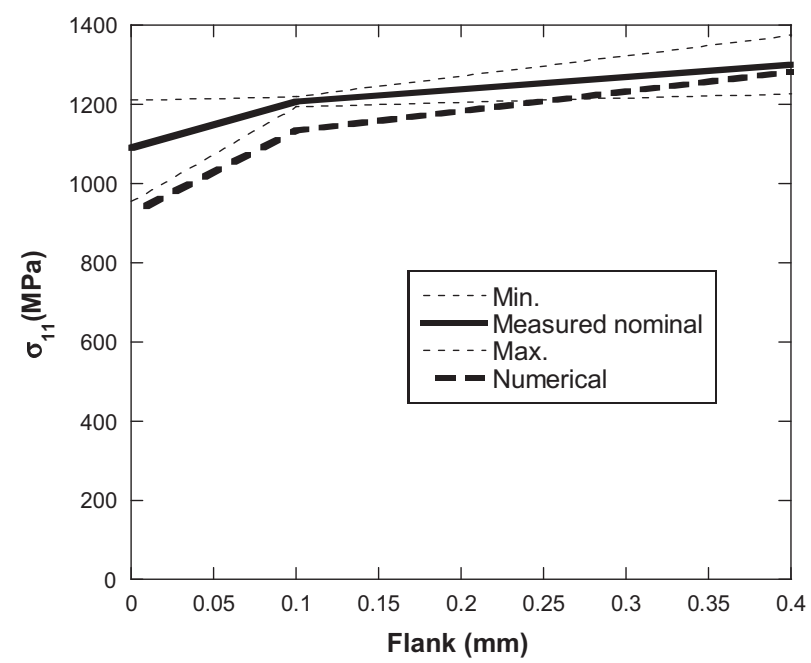

Fig. 9. Influence of flank wear in circumferential residual stresses at machined surface (doted lines show measurement uncertainty).
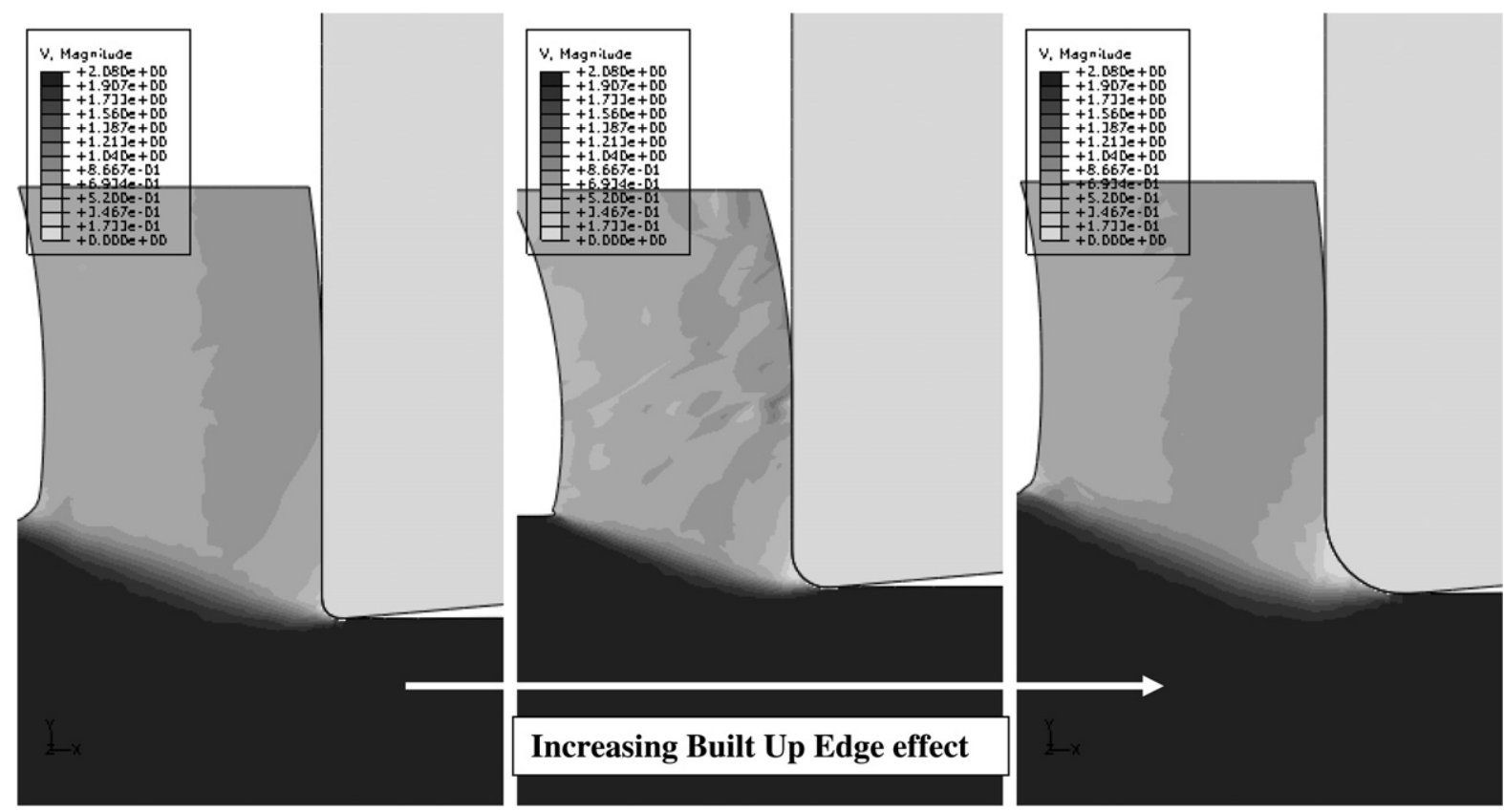

Fig. 10. Velocity field obtained with different cutting edge radius. 
The accuracy reached with the model is considered reasonably when compared with differences between experimental and predicted values usually obtained with models presented in scientific literature.

\subsection{Flank wear}

Flank wear is commonly observed in cutting tools when machining austenitic steels. Two levels of flank wear have been modelled, flank length equal to 0.1 and $0.4 \mathrm{~mm}$. The length of the flank increases with cutting time and it is usually related in current processes in industry with increased friction heat generated at the machined surface. The increment of temperature in this zone (see Fig. 8), leads to increase the level of residual stress due to the effect of thermal expansion. The level of residual stress at machined surface is significantly increased as flank wear evolves (see Fig. 9).
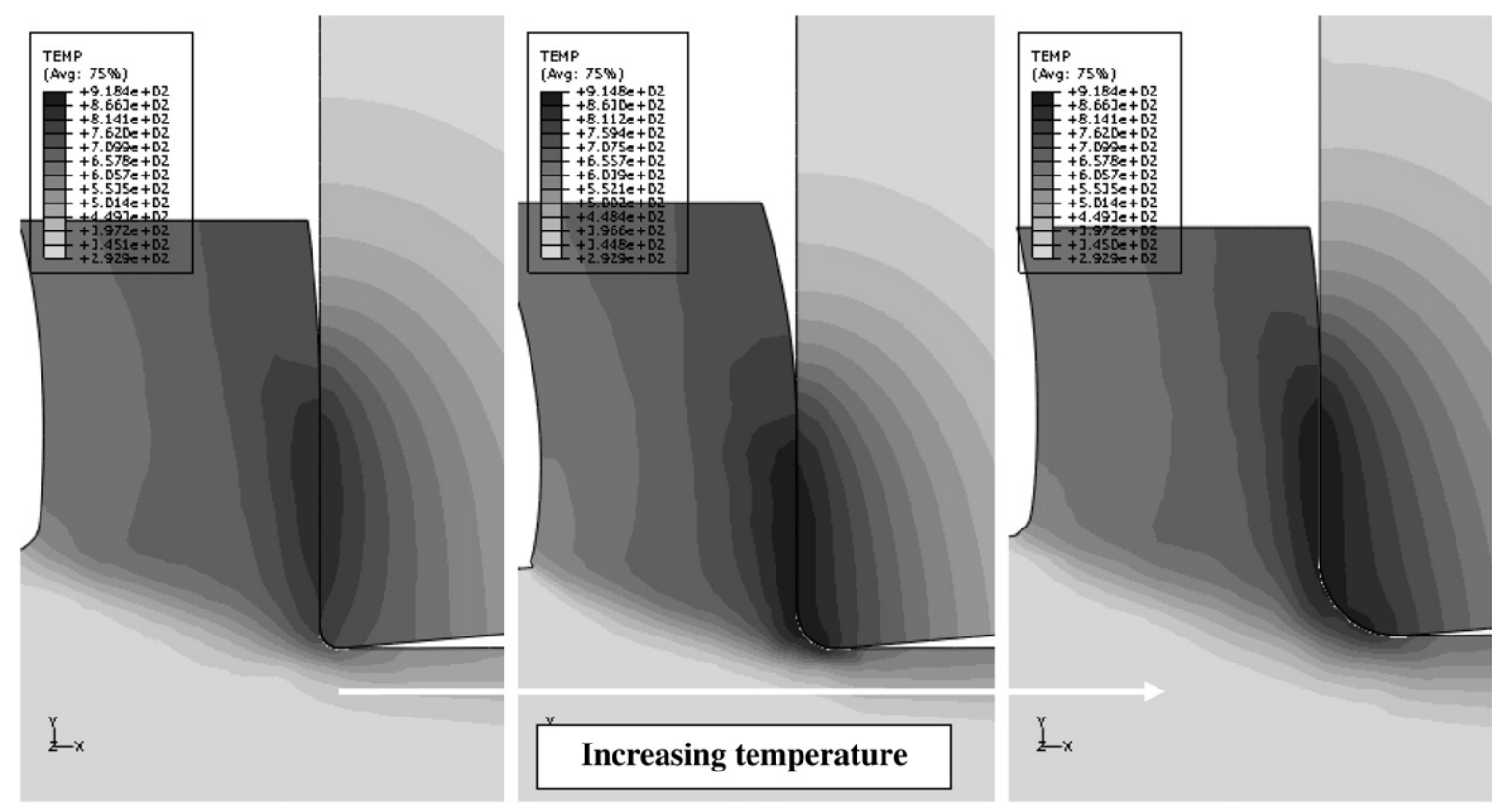

Fig. 11. Temperature field obtained with different cutting edge radius.

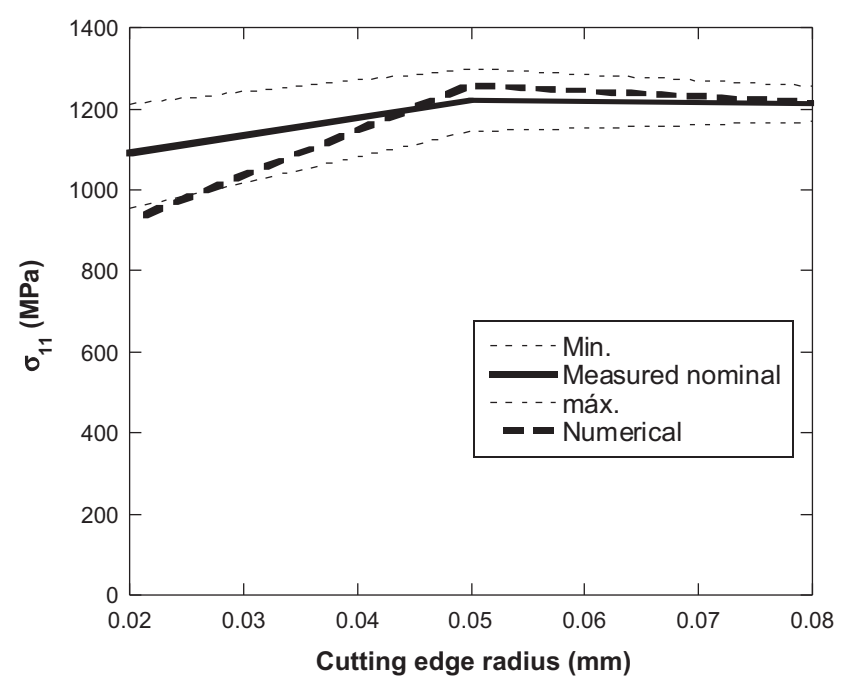

Fig. 12. Influence of rounded cutting edge in circumferential residual stresses at machined surface (doted lines show measurement uncertainty). 


\subsection{Rounded cutting edge}

When the tool tip is rounded the effective rake angle is changed. Negative rake angle is related with a decreased level of tensile residual stress, due to the effect produced by the stagnation zone in the interface chip/tool [2]. It is possible to deduce from Fig. 10 that increasing the cutting edge radius, also increases the zone where the velocity magnitude is very small providing an effective value of the rake angle that was smaller than the real value. This effect resulted in compressive stresses which lowered the level of the residual stresses. This effect was added to the thermal softening produced because of the
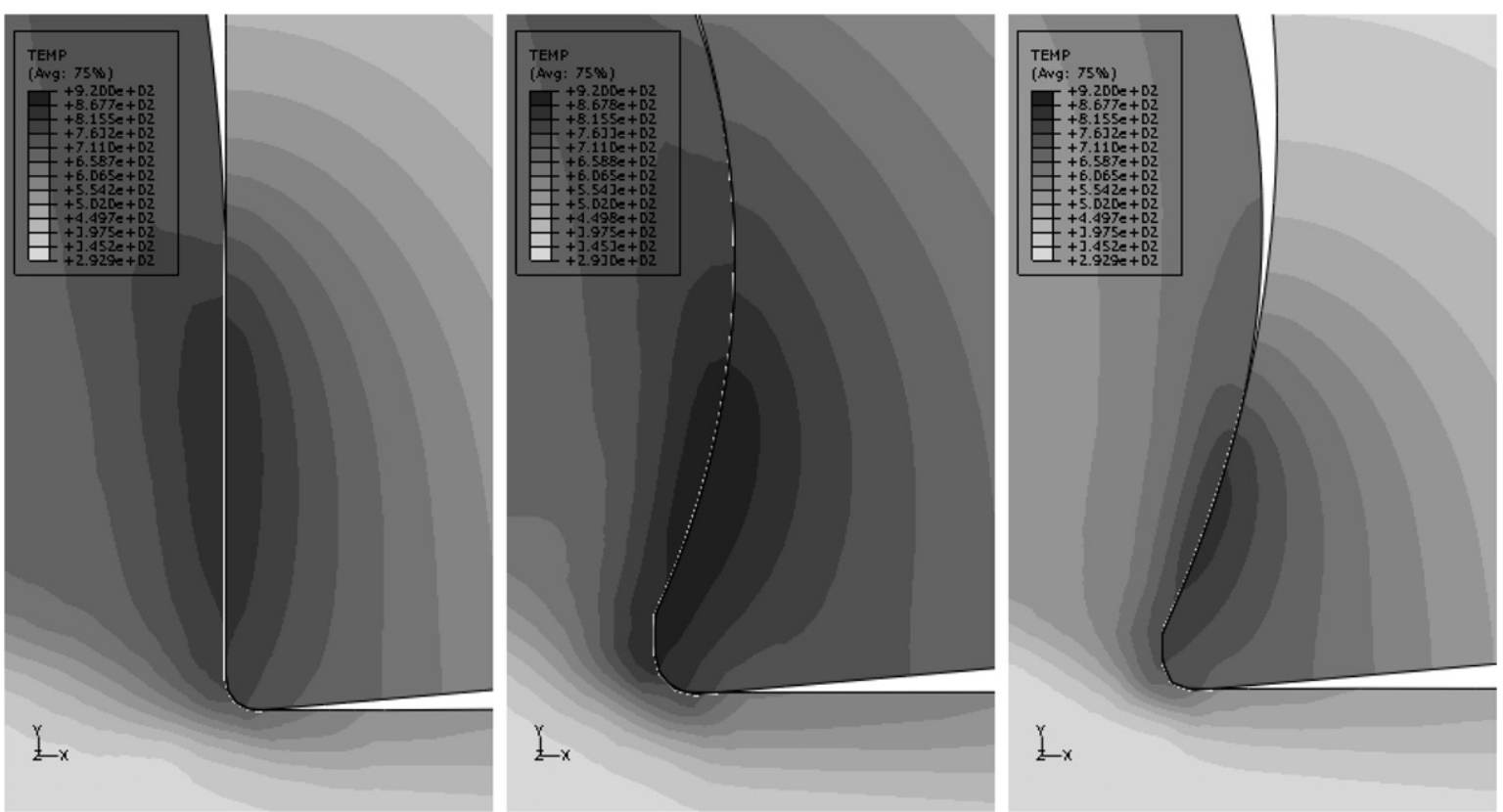

Fig. 13. Temperature field obtained with different craters.
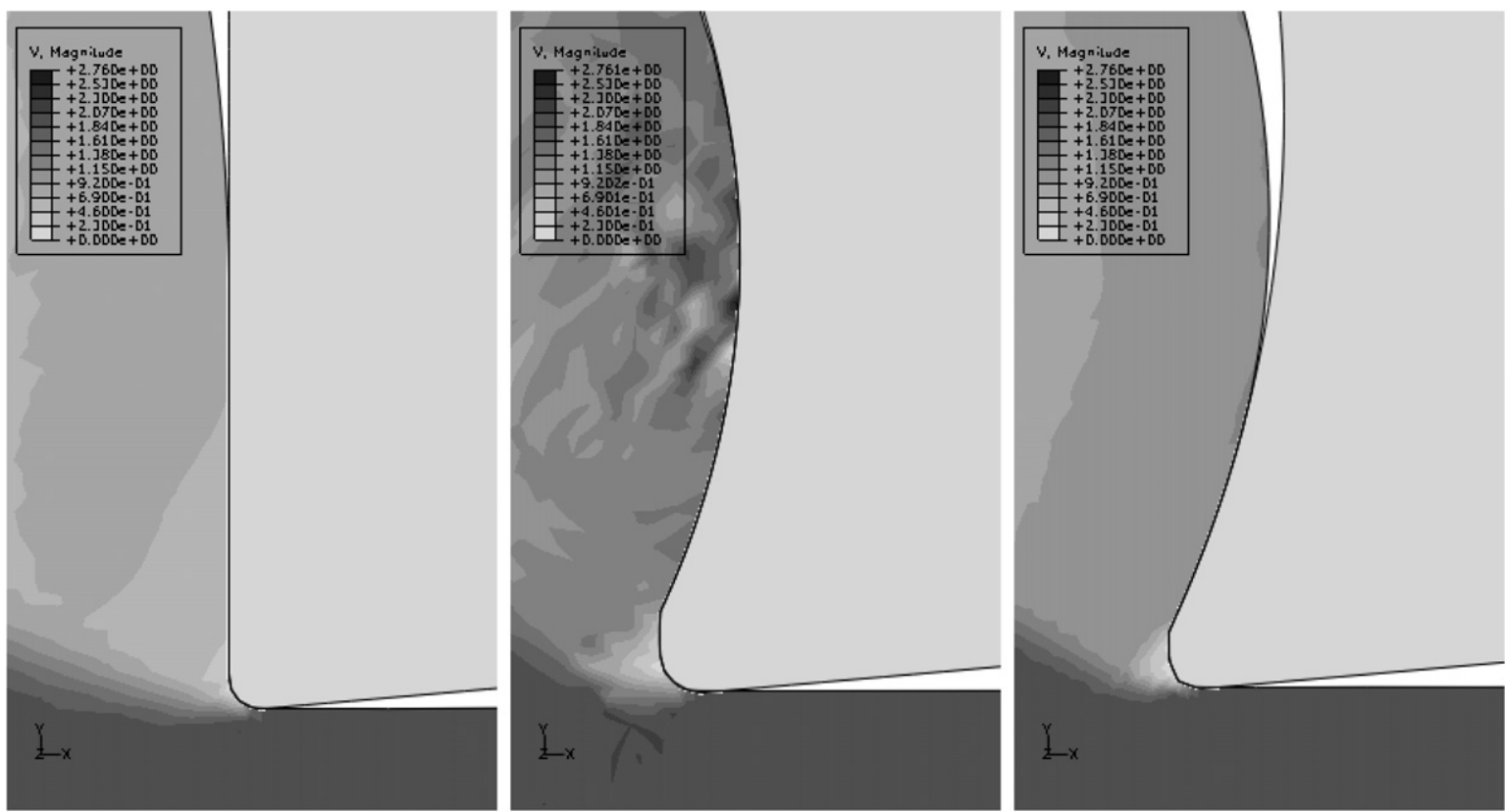

Fig. 14. Velocity field obtained with different crater wear. 


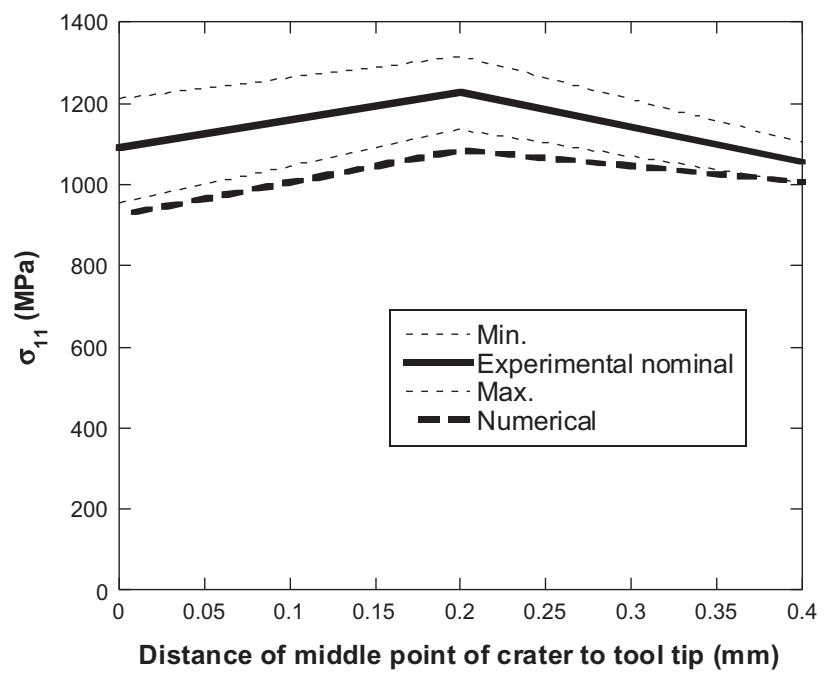

Fig. 15. Influence of crater in circumferential residual stresses at machined surface (doted lines show measurement uncertainty).

increased plastic work. However this phenomenon was also related with increased level of temperature (see Fig. 11 showing temperature field during cutting) and the subsequent increment of the thermal expansion effect.

In this work three values of rounded cutting edge have been analysed (cutting edge radius equal to reference value 0.02 ; 0.05 and $0.08 \mathrm{~mm}$ ). Residual stress resulted from the competition of the factors described previously. The predicted level of tensile residual stress in machined surface (Fig. 12) is raised when the radius was increased from the initial value to $0.05 \mathrm{~mm}$, showing dominant effect of the thermal expansion contribution. However when the radius increased up to the maximum value of $0.08 \mathrm{~mm}$ the predicted tensile stress level in the machined surface remained almost unchanged, showing the prevalent influence of thermal softening and effective rake angle.

\subsection{Crater wear}

Crater wear is due to abrasive wear in rake surface. The presence of the crater results in an increment of effective rake angle close to the cutting edge. However in the zone of the crater far from the cutting edge the rake angle is decreased (see Fig. 5). On the other hand depending on the relative size of the uncut chip thickness respect to the crater size, the contact length could be increased influencing the maximum temperature.

Two geometries of crater were selected (see Fig. 5d) corresponding to current levels of crater wear in machining operations. Fields of temperature and velocity during cutting are shown respectively in Figs. 13 and 14. Due to the similar geometry of the tool close to the tool tip (rake angle equal to zero) differences in the stagnation zone are not relevant for all cases analysed.

The influence of the increased temperature seems to be prevalent in the first crater since leading to an increment of tensile residual stress (see Fig. 15). The shape of the second crater, with a decreased contact area at the interface tool-chip, resulted in a decreased level of residual stress.

\section{Conclusions}

Machining induced residual stresses are important parameters that characterize surface integrity and depend on different coupled phenomena. Some of these influencing factors (cutting speed, friction, rake angle) have been analysed in previous works of the authors $[2,40]$. In the present study, cutting speed and friction are fixed, and the tool geometry was varied in order to analyse the influence of worn geometry during cutting.

Both numerical and experimental approaches have been included in the work.

Finite element method was applied successfully to predict machining induced residual stresses. The numerical model was developed using the commercial code ABAQUS, using ALE approach and both explicit and implicit integration schemes. The model has been satisfactory applied to predict machining residual stresses induced in AISI $316 \mathrm{~L}$ with different types and levels of tool wear.

Orthogonal cutting tests were performed in similar conditions to those imposed in simulations. The worn geometry was artificially generated by EDM in order to control the wear level in each insert cutting. The FE model was validated comparing numerical predictions with the distribution of residual stresses measured in-depth in the work piece for two different geometries of the tool: new and rounded cutting edge. Also for every type of tool wear analysed, resultant residual stresses 
predicted with the numerical simulation were compared with experimental measurements at machined surface, showing reasonably accuracy of the model.

Main conclusion of the work is that all types of wear lead to increased residual stress when compared with the reference geometry, being this one of the undesired effects of tool wear during machining operations. Similar qualitative trend was shown with both experimental and numerical approaches.

Concerning the accuracy of the model when predicting residual stresses, Figs. 9, 12 and 15, show the comparison between measurements including uncertainty and the numerical results. Differences between predicted and measured values of tensile residual stresses, ranging from $0 \%$ to $15 \%$, are reasonably values for this application.

\section{Acknowledgements}

The authors are indebted for the financial support of this work, to the Ministry of Science and Education of Spain (under Project DPI2008-06746). The authors also acknowledge to the CAM-UC3M for the financial support obtained for this work with the Project CCG08-UC3M/DPI-4494.

\section{References}

[1] M. Mohammadpour, M.R. Razfar, R. Jalili Saffar, Numerical investigating the effect of machining parameters on residual stresses in orthogonal cutting, Simulat. Modell. Pract. Theory 18 (2010) 378-389.

[2] H. Miguélez, R. Zaera, A. Molinari, R. Cheriguene, A. Rusinek, Residual stresses in orthogonal cutting of metals: the effect of thermomechanical coupling parameters and of friction, J. Therm. Stresses 32 (2009) 1-20.

[3] W. Grzesik, Advanced Machining Processes of Metallic Materials, Theory Modelling and Applications, Elsevier Science, Amsterdam (Nederland), 2008. pp. $163-181$.

[4] J.C. Outeiro, A.M. Dias, I.S. Jawahir, On the effects of residual stresses induced by coated and uncoated cutting tools with finite edge radii in turning operations, Ann. CIRP 55 (1) (2006) 111-116.

[5] C.R. Liu, M.M. Barash, Variables governing patterns of mechanical residual stress in a machined surface, J. Eng. Ind. Trans. ASME 104 (1982) 257-264.

[6] M. Liu, J. Takagi, A. Tsukuda, Effect of tool nose radius and tool wear on residual stress distribution in hard turning of bearing steel, J. Mater. Process. Technol. 150 (2004) 234-241.

[7] J.D. Thiele, S.N. Melkote, R.A. Peascoe, T.R. Watkins, Effect of cuttingedge geometry and workpiece hardness on surface residual stresses in finish hard turning of AISI 52100 steel, J. Manuf. Sci. Eng. Trans. ASME 122 (2000) 642-649.

[8] R.M. Arunachalam, M.A. Mannan, A.C. Spowage, Surface integrity when machining age hardened inconel 718 with coated carbide cutting tools, Int. J. Mach. Tools Manuf. 44 (2004) 1481-1491.

[9] L. Chen, T.I. El-Wardany, W.C. Harris, Modelling the effects of flank wear land and chip formation on residual stresses, CIRP Ann. 53 (2004) 95-98.

[10] J. Hua, D. Umbrello, R. Shivpuri, Investigation of cutting conditions and cutting edge preparations for enhanced compressive subsurface residual stress in the hard turning of bearing steel, J. Mater. Process. Technol. 171 (2006) 180-187.

[11] J.C. Outeiro, D. Umbrello, R. M'Saoubi, Experimental and numerical modelling of the residual stresses induced in orthogonal cutting of AISI 316 L steel, Int. J. Mach. Tools Manuf. 46 (14) (2006) 1786-1794

[12] M N.A. Nasr, E.-G. Ng, M.A. Elbestawia, Modelling the effects of tool-edge radius on residual stresses when orthogonal cutting AISI 316 L, Int. J. Machine Tools Manuf. 47 (2007) 401-411.

[13] M. Salio, T. Berruti, G. De Poli, Prediction of residual stress distribution alter turning in turbine disks, Int. J. Mech. Sci. 48 (2006) $976-984$.

[14] Y. Dogu, E. Aslan, N. Camuscu, A numerical model to determine temperature distribution in orthogonal metal cutting, J. Mater. Process. Technol. 171 (2006) 1-9.

[15] L. Filice, D. Umbrello, F. Micari, L. Settineri, On the finite element simulation of thermal phenomena in machining processes, Adv. Meth. Mater. Form. (2007) 273-288.

[16] A.G. Mamalis, M. Horvath, A.S. Branis, D.E. Manolakos, Finite element simulation of chip formation in orthogonal metal cutting, J. Mater. Process. Technol. 110 (2001) 19-27.

[17] D. Umbrello, L. Filice, S. Rizzuti, F. Micari, On the evaluation of the global heat transfer coefficient in cutting, Int. J. Mach. Tools Manuf. 47 (2007) 17381743.

[18] Z.-C. Lin, Y.-Y. Lin, C.R. Liu, Effect of thermal load and mechanical load on the residual stress of a machined workpiece, Int. J. Mech. Sci. 33 (4) (1991) $263-278$.

[19] M.N.A. Nasr, E.-G. Ng, M.A. Elbestawi, A modified time-efficient FE approach for predicting machining-induced residual stresses, Finite Elem. Anal. Des. 44 (2008) 149-161.

[20] P.J. Arrazola, D. Ugarte, X. Dominguez, A new approach for the friction identification during machining through the use of finite element modelling, Int. J. Mach. Tools Manuf. 48 (2008) 173-183.

[21] H. Miguélez, A. Muñoz-Sánchez, J.L. Cantero, J.A. Loya, An efficient implementation of boundary conditions in an ale model for orthogonal cutting, J. Theor. Appl. Mech. 47 (3) (2009) 1-20.

[22] T.D. Marusich, M. Ortiz, Modelling and simulation of high-speed machining, Int. J. Numer. Meth. Eng. 38 (1995) 3675-3694.

[23] M.H. Dirikolu, T.H.C. Childs, K. Maekawa, Finite element simulation of chip flow in metal machining, Int. J. Mech. Sci. 43 (2001) $2699-2713$.

[24] T. Özel, E. Zeren, Finite element modelling of stresses induced by high speed machining with round edge cutting tools, in: Proceedings of IMECE'05, November 5-11, Orlando, Florida, 2005.

[25] H. Miguélez, R. Zaera, A. Rusinek, A. Moufki, A. Molinari, Numerical modelling of orthogonal cutting: influence of cutting conditions and separation criterion, J. Phys. IV (134) (2006) 417-422.

[26] O. Pantalé, J.-L. Bacaria, O. Dalverny, R. Rakotomalala, S. Caperaa, 2D and 3D numerical models of metal cutting with damage effects, Comput. Meth. Appl. Mech. Eng. 193 (2004) 4383-4399.

[27] Hibbit Karlson and Sorensen Inc., ABAQUS User's Manual 6.4-1, 2003.

[28] G. Barrow, A review of experimental and theoretical techniques for assessing cutting temperatures, Ann. CIRP 22 (2) (1973) $203-211$.

[29] C. Maranhão, J. Paulo Davim, Finite element modelling of machining of AISI 316 steel: numerical simulation and experimental validation, Simulat. Modell. Practice Theory 18 (2010) 139-156.

[30] Z.C. Lin, S.Y. Lin, A couple finite element model of thermo-elastoplastic large deformation for orthogonal cutting, ASME J. Eng. Indus. 114 (1992) 218226.

[31] G.R. Johnson, W.H. Cook, A constitutive model and data for metals subjected to large strains, high strain rate and temperature, in: Proceedings of the International Symposium of Ballistics, 1983, pp. 541-547.

[32] D. Umbrello, R. M'Saoubi, J.C. Outeiro, The influence of Johnson-Cook material constants on finite element simulation of machining of AISI 316 L steel, Int. J. Mach. Tools Manuf. 47 (2007) 462-470 
[33] N. Tounsi, J. Vincenti, A. Otho, M.A. Elbestawi, From the basics of orthogonal metal cutting toward the identification of the constitutive equation, Int. J. Mach. Tools Manuf. 42 (2) (2002) 1373-1383.

[34] D.Y. Jang, T.R. Watkins, K.J. Kozaczek, CR. Hubbard, O.B. Cavin, Surface residual stresses in machined austenitic stainless steel, Wear 194 (1996) 168173.

[35] A. Muñoz-Sánchez, Análisis experimental y numérico de las tensiones residuales debidas a mecanizado en aceros inoxidables austeníticos, Tesis Doctoral, 2008 (in Spanish).

[36] http://www.ideko.es/.

[37] I.C. Noyan, J.B. Cohen, Residual Stress-measurement by Diffraction and Interpretation, Society for Experimental Mechanics, Springer-Verlag, New York, 1987.

[38] J.C. Outeiro, K.C. Ee, O.W. Dillon Jr., P.C. Wanigarathne, I.S. Jawahir, Some observations on comparing the modeled and measured residual stresses on the machined surface induced by orthogonal cutting of AISI $316 \mathrm{~L}$ steel, in: Proceeding of the 9th CIRP International Workshop on Modeling of Machining Operations, Bled, Slovenia, 2006.

[39] I. Korkut, M. Kasap, I. Ciftci, U. Seke, Determination of optimum cutting parameters during machining of AISI 304 austenitic stainless steel, Mater. Des. 25 (2004) 303-305.

[40] M.H. Miguélez, R. Zaera, A. Molinari, A. Muñoz-Sánchez, The influence of cutting speed in the residual stresses induced by HSM in AISI 316 L steel, in: 12th CIRP Conference on Modelling of Machining Operations, San Sebastián, España, 7-8 May, 2009. 